\title{
Soil Moisture in the Climate System
}

\author{
Lecture slides by Randal Koster, Global Modeling and \\ Assimilation Office, NASA/GSFC, Greenbelt, MD, USA \\ randal.d.koster@nasa.gov
}

Our Warming Planet: Topics in Climate Dynamics Lectures in Climate Change, Vol. 1 2017 


\section{Soil Moisture in the Climate System}

The moisture in the top two meters or so of soil is a tiny fraction $(<0.01 \%)$ of the Earth's water. However, because it lies at the interface between the land and atmosphere, it has an inordinate impact on climate and its variability.

Atmospheric processes

Surface and subsurface hydrologic processes
Surface soil moisture controls:

(i) Precipitation $(\mathrm{P})$ partitioning: $\boldsymbol{P}=\boldsymbol{E}+\boldsymbol{Q}+\boldsymbol{\Delta}$ water storage $E=$ evapotranspiration $Q=$ runoff

(ii) Net radiation $\left(\mathrm{R}_{\text {net }}\right)$ partitioning:

$$
\begin{gathered}
\boldsymbol{R}_{\mathbf{n e t}}=\lambda \boldsymbol{E}+\boldsymbol{H}+\boldsymbol{\Delta} \text { energy storage } \\
H=\text { sensible heat flux } \\
\lambda=\text { latent heat of vaporization }
\end{gathered}
$$




\section{How Does Soil Moisture Affect Climate Variability?}

Through its impact on the surface energy and water balances, as characterized by its impact on evapotranspiration.

For example:

Wet soil $\Rightarrow$ higher evap., lower sensible heat flux

This can affect local air temperature:

$\Rightarrow$ more evaporative cooling

$\Rightarrow$ lower air temperature

Wet Soil

It can also affect local precipitation:

$\Rightarrow$ boundary layer modification

$\Rightarrow$ conditions more conducive

(or perhaps less conducive)

to onset of moist convection 


\section{Conventional Wisdom Regarding Control of Soil Moisture on Evapotranspiration}

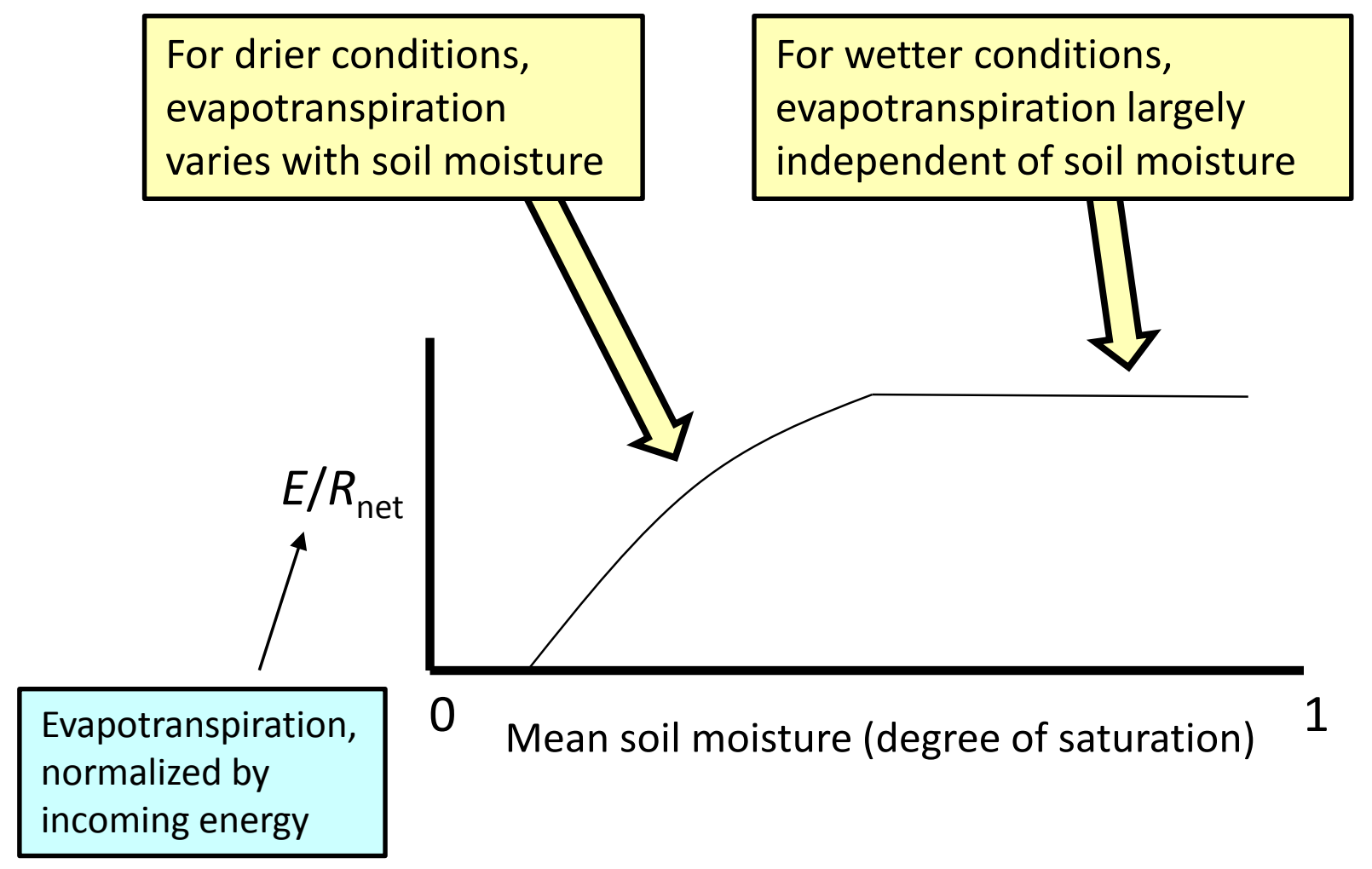

Relevant observations are rare, but where they exist, they support this idea....

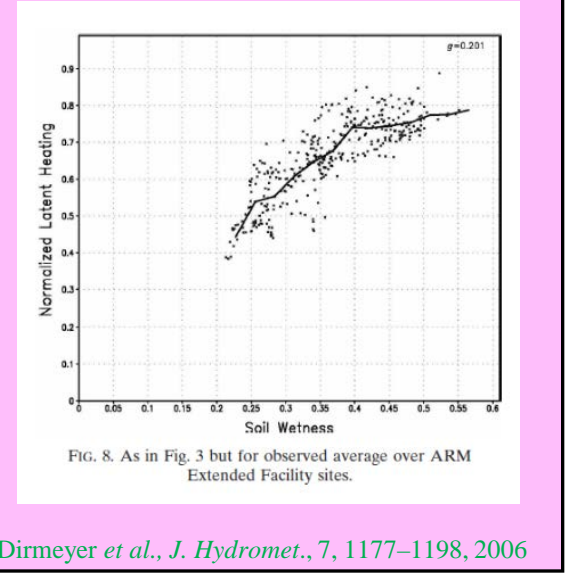


Because of this relationship, the connection between soil moisture and the atmosphere (through the former's effect on evapotranspiration) is strongest in the transition zones between dry and wet areas.

Shown here: results from the multi-model GLACE experiment. Indicated is where soil moisture variability helps guide short-term boreal summer rainfall variability.

Why are the transition areas important? See next slide, which focuses on North America...

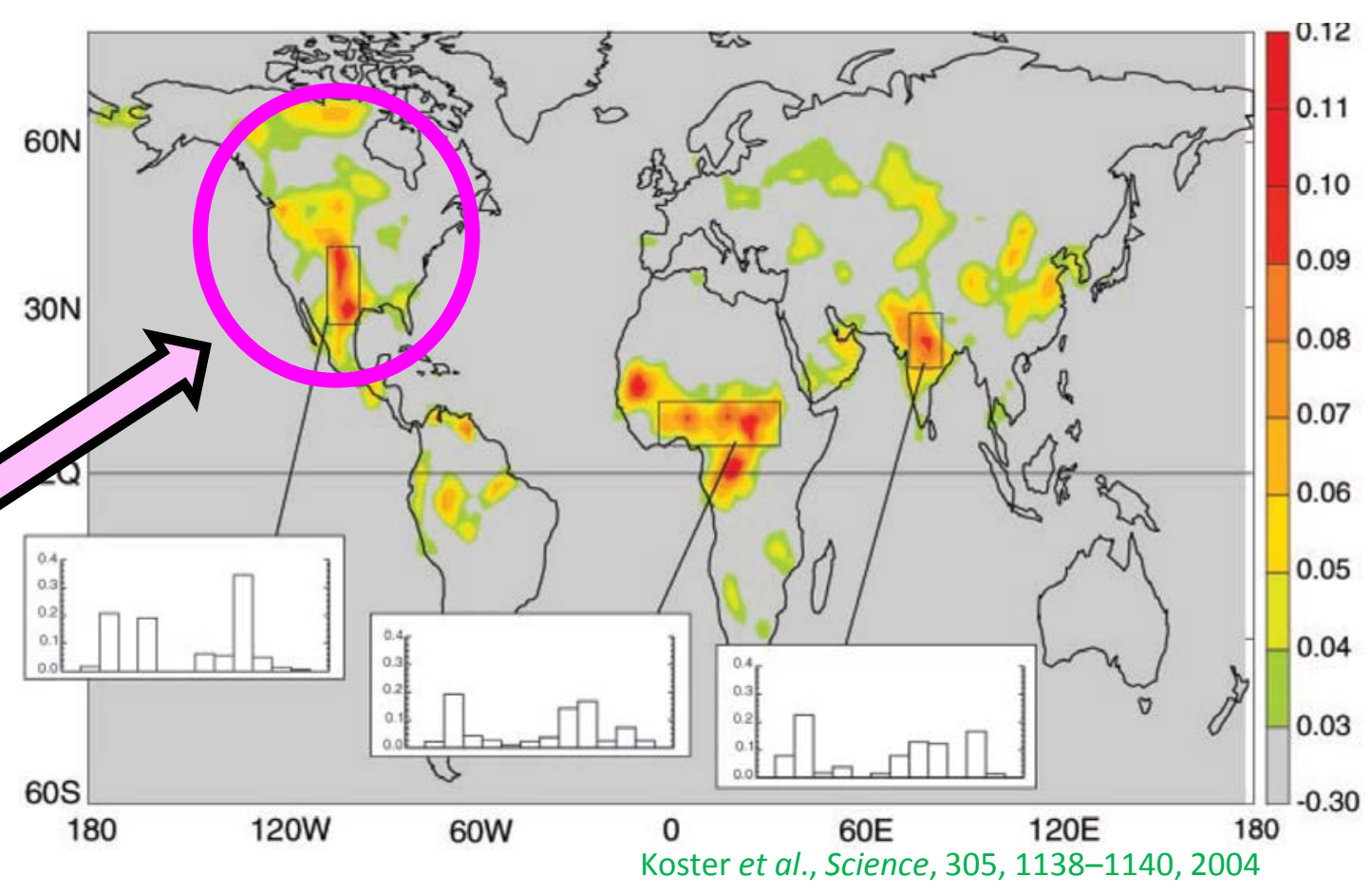




\section{Explanation for Why Soil Moisture Feedback on the Atmosphere is Strongest in Transition Zones}

When it is really dry, $E$ is too small (and varies too little) to have an effect.
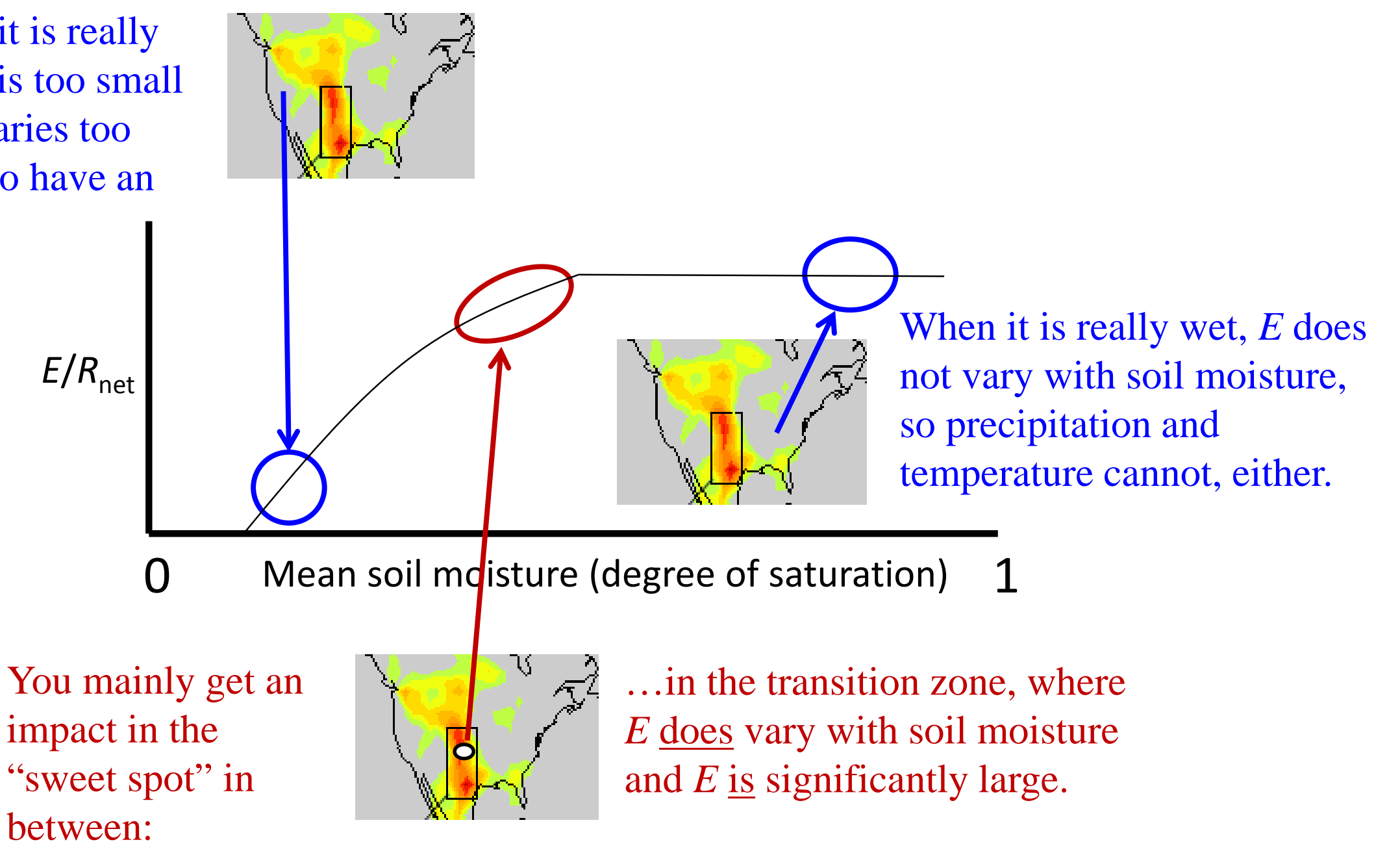


\section{Direct evapotranspiration measurements are too sparse to show this pattern. However, the pattern is seen in measurements of E-related proxy variables.}

Wanted: indication of where interannual variability of $E$ is large. Plot instead: interannual variability of well-measured variables that vary with $E$. (Plot $\sigma_{X}^{2} \operatorname{Corr}^{2}(X, W)$, where $X$ is the proxy variable and $W$ characterizes water availability.)
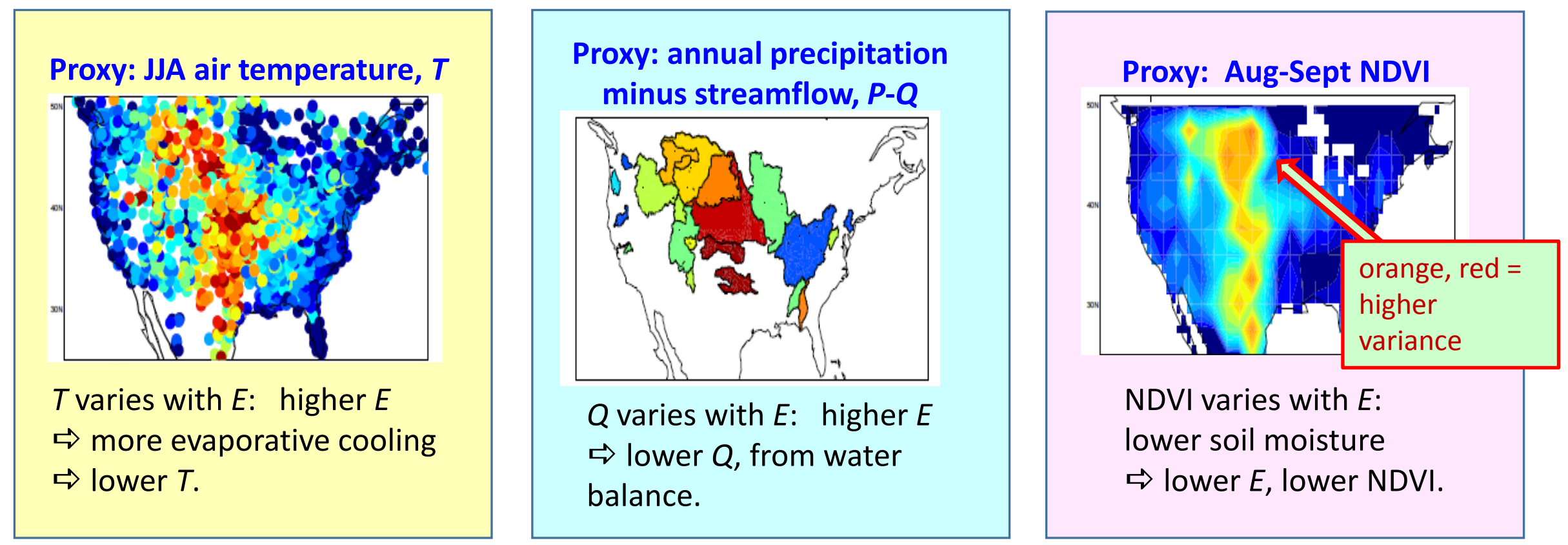

Koster et al., Frontiers in Earth Science, 2015 


\section{Soil Moisture in a Changing Climate}

Climate change may lead to a shift in a region's hydroclimatic regime.

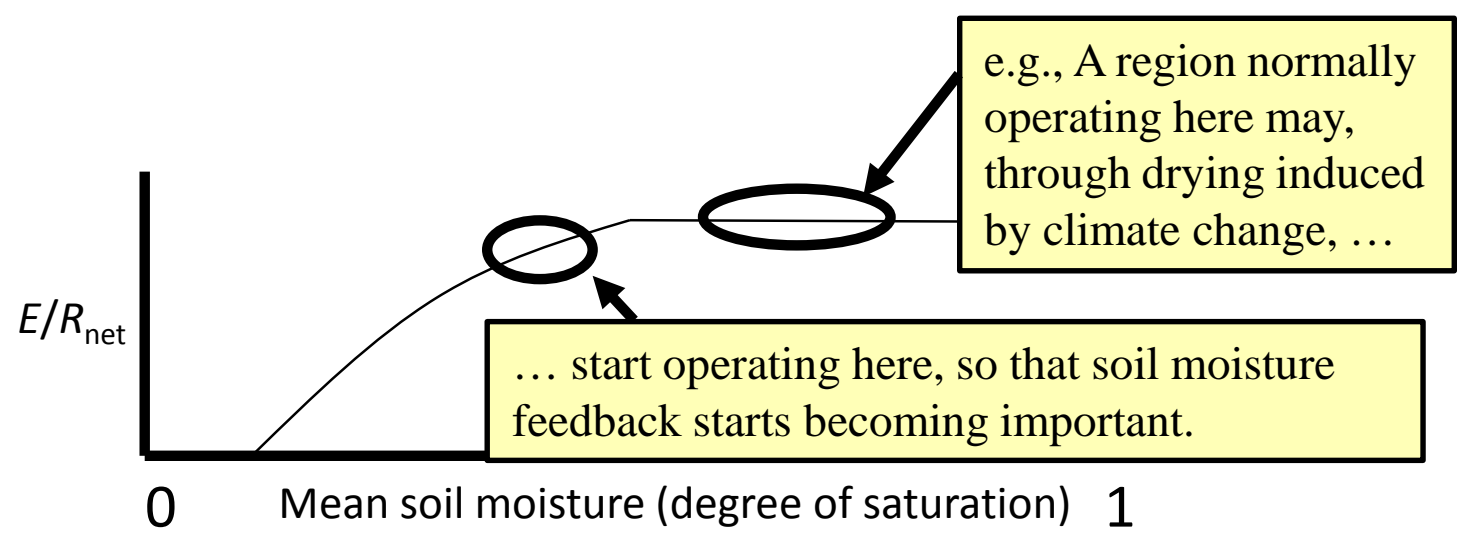

Models suggest such a shift in Europe, with soil moisture having a larger impact on climate variability during future climate.

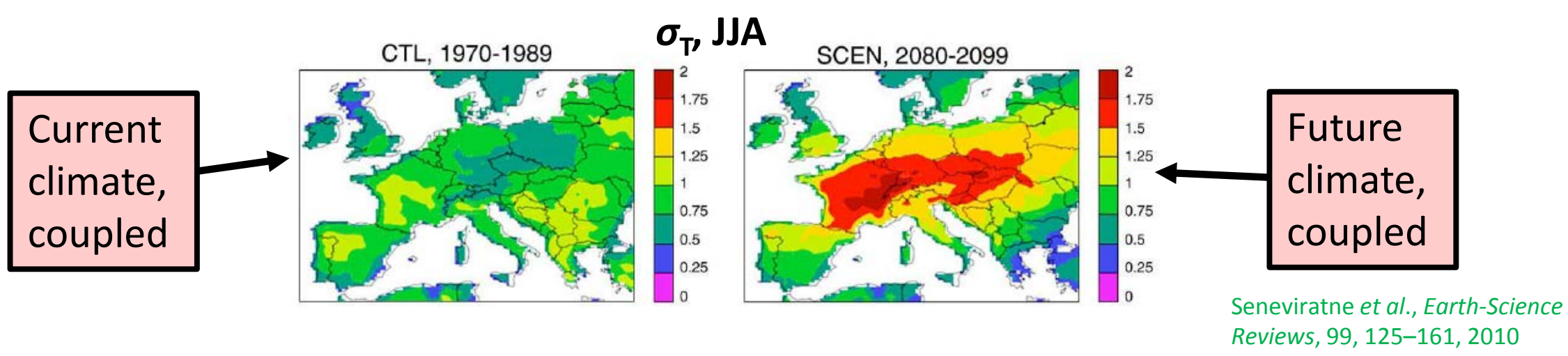




\section{Another relevant property of soil moisture: “memory". If the}

soil is anomalously wet today, it will probably be anomalously wet tomorrow, next week, and maybe even next month.

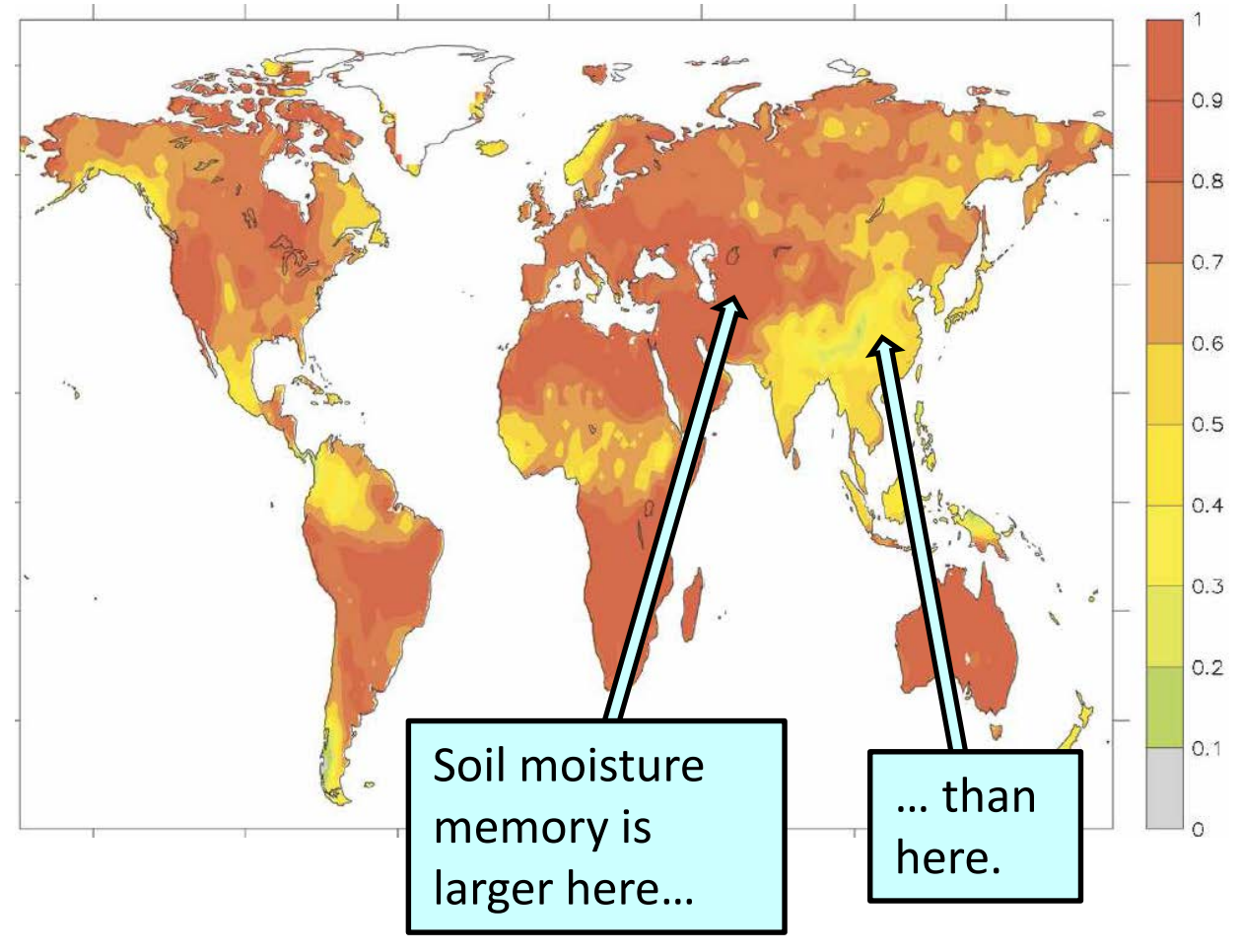

$\hookleftarrow$ Multi-model estimate of 27day-lagged autocorrelation of soil moisture (boreal summer).

Observed estimates for individual locations are sparse, but where they exist, the models roughly agree with them. 


\section{This memory, in combination with soil moisture's ability to feed back on the atmosphere, has an important implication:}

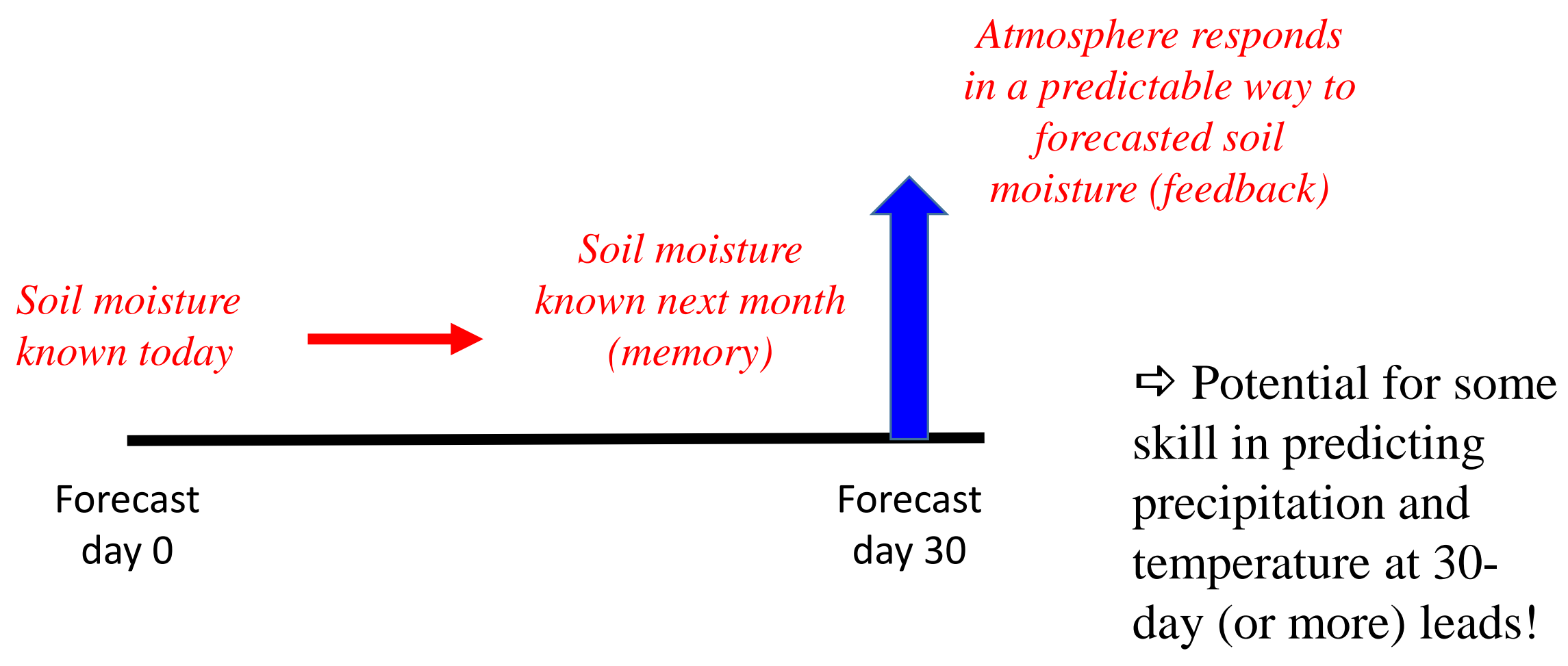




\section{Estimations of Forecast Skill Associated with Soil Moisture Initialization}

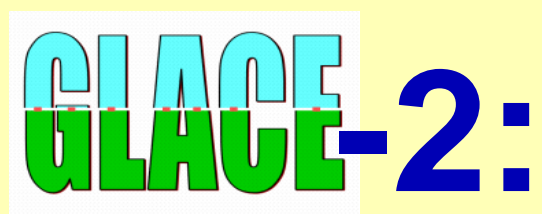

The second phase of the Global Land-Atmosphere Coupling Experiment (an international, multi-institution project)

Koster et al., J. Hydromet., 12, 804-822, 2011

Gist of experiment:

1. Perform two sets of forecast simulations:

(i) with accurate soil moisture initial conditions (ICs)

(ii) without accurate soil moisture ICs

2. Compare forecasted $P, T$ to obs.

3. Compute soil moisture contribution to forecast skill:

Skill from simulations w/ accurate land ICs
Skill from simulations w/o accurate land ICS
Skill due to land ICs 


\section{GLACE-2 Results: ‘Consensus' Skill Contribution from Land Initialization (JJA)}

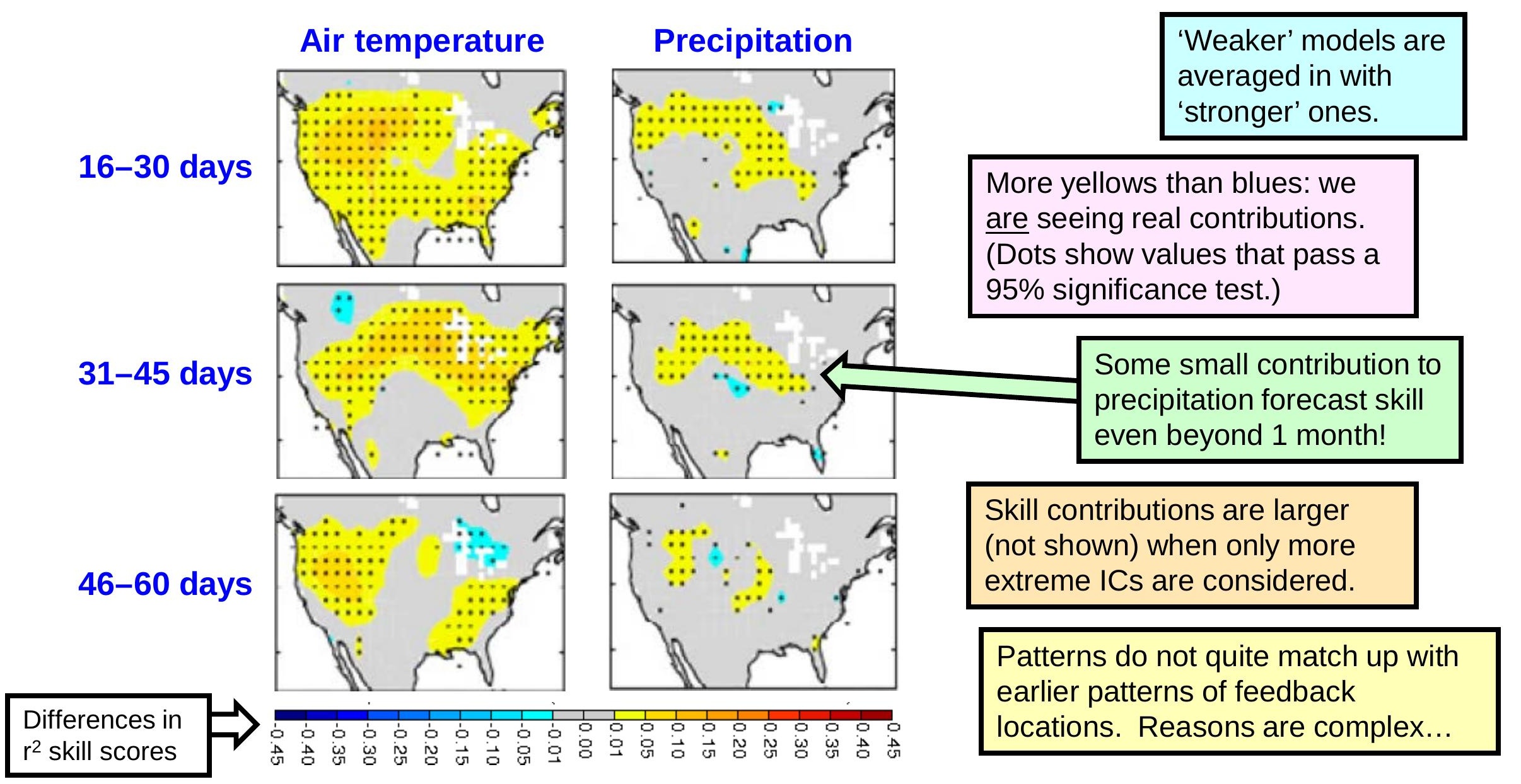




\section{Soil Moisture and Streamflow Forecast Skill}

Snow (or rainfall) over wet soil: most of the meltwater runs off into streams, reservoirs.

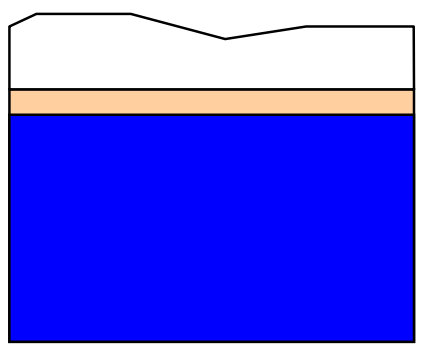

Snow (or rainfall) over dry soil: much of the meltwater infiltrates the soil and is lost to evapotranspiration $\Rightarrow$ less to streams, reservoirs.

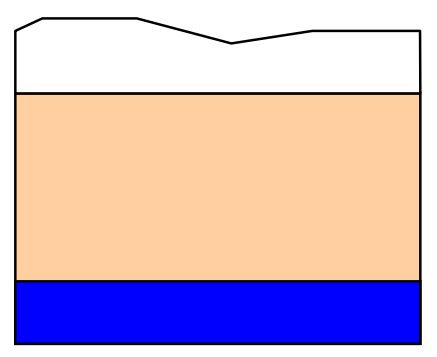

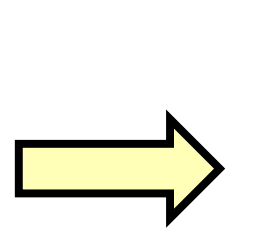

Knowledge of winter

soil moisture, coupled

with soil moisture memory, provides springtime streamflow forecast skill.
Forecast experiment: compute skill of March-July streamflow forecasts (vs. obs) associated solely with accurate soil moisture initialization:

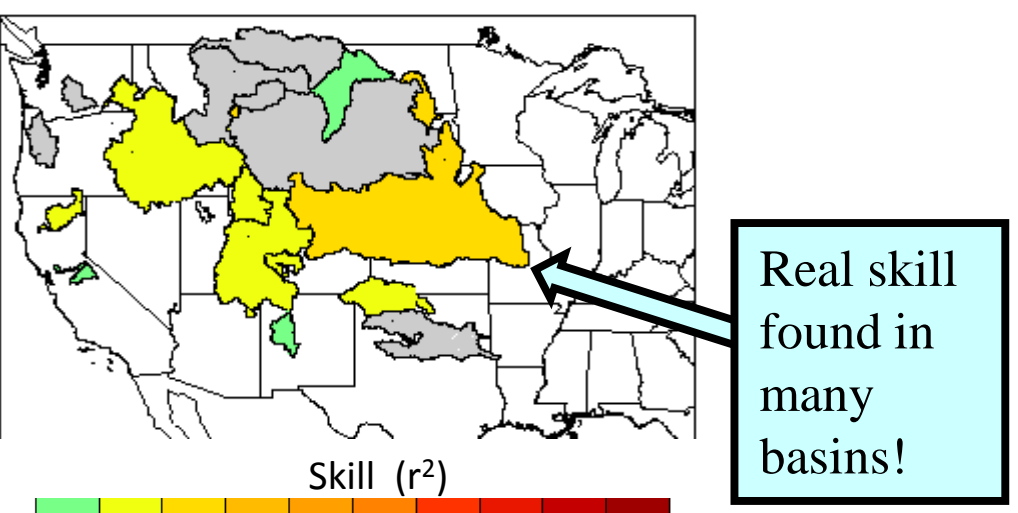

Koster et al., Nature Geoscience, 3, 613-616, 2010. 


\section{Soil Moisture in Earth System Models}

How can we initialize soil moisture, e.g., for forecasts? From direct, in situ observations?

No. In situ observations (certainly across large areas) are sparse to non-existent.

Modeling approach: Force a gridded array of land surface model elements with arrays of observations-based meteorological forcing $\Rightarrow$ let modeled soil moistures evolve in response to the forcing.

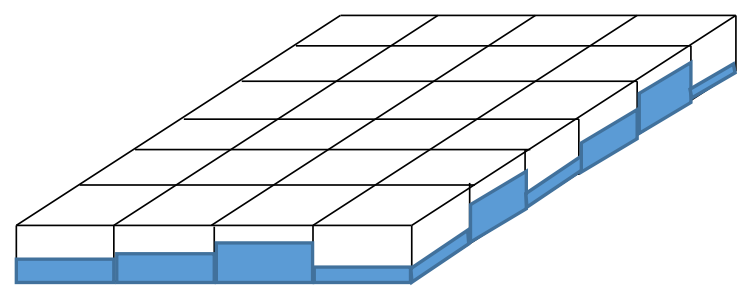

Array of soil moistures at beginning of time period (crude representation)

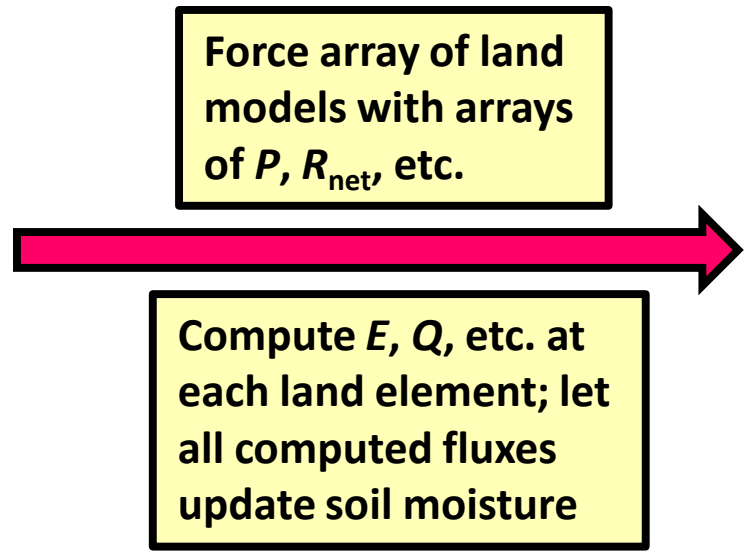

Array of soil moistures at end of time period: reflects antecedent meteorology 


\section{Soil Moisture in Earth System Models}

Even better approach: Combine modeling and observations through data assimilation:
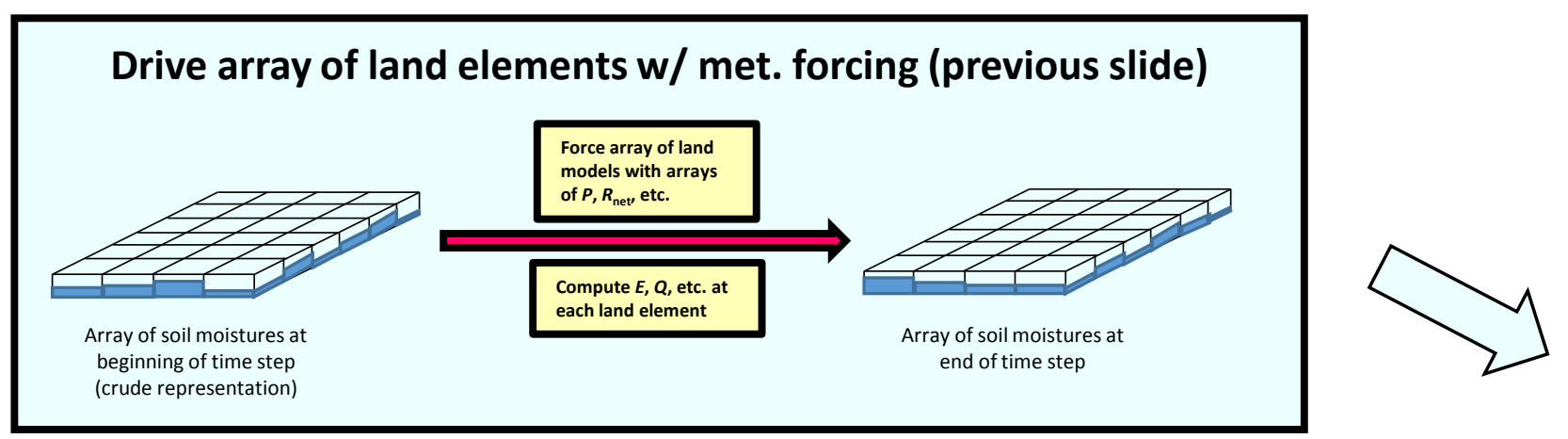

Optimally combine these estimates, using rigorous mathematical procedures $\Rightarrow$ a soil moisture field that

Obtain satellite-based estimate of, e.g., soil moisture in top few is more accurate than either the modeled field or the satellite-based field centimeters. alone. 


\section{Soil Moisture in Earth System Models}

New satellite-based L-band sensors have the potential to provide valuable global soil moisture data $\Rightarrow$ A renaissance in soil moisture estimation through assimilation?
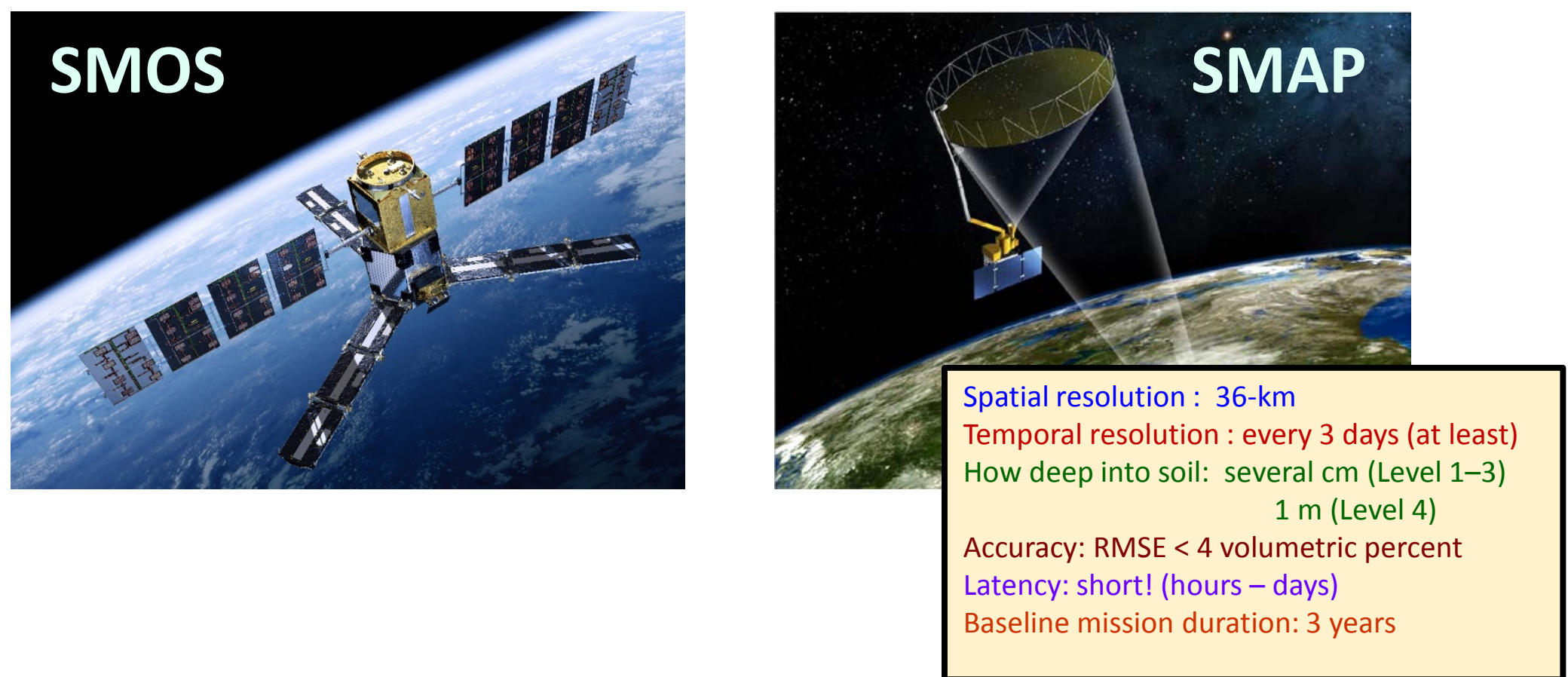


\section{Soil Moisture in Earth System Models: Some Caveats}
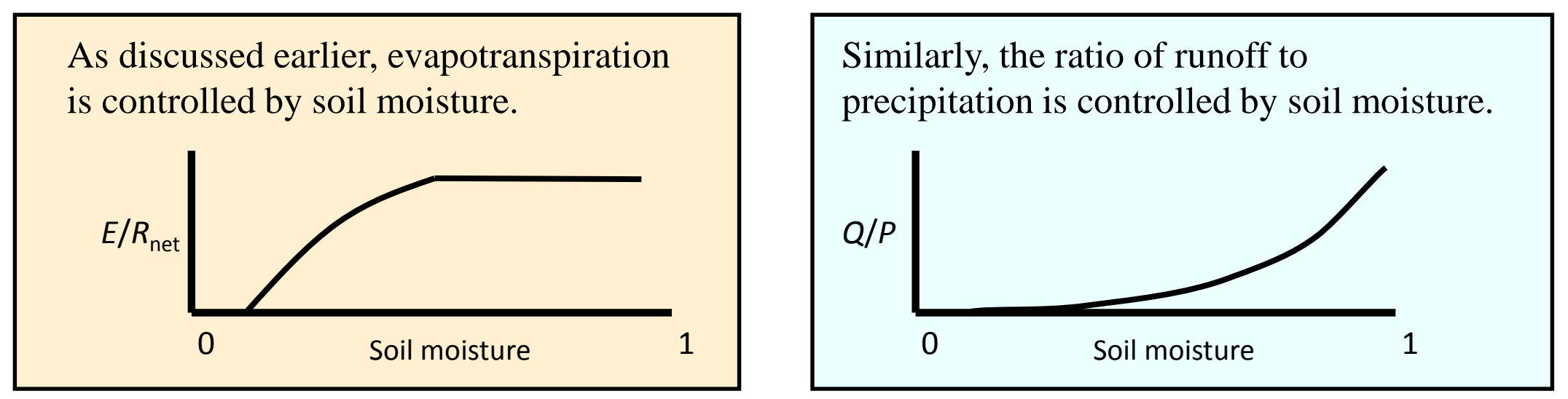

A land surface model has multiple complex formulations that interact with each other, implicitly producing some form of these two relationships (approximate-scatter will be large around them).

It is the interaction between these underlying relationships that determines how a land surface model behaves.

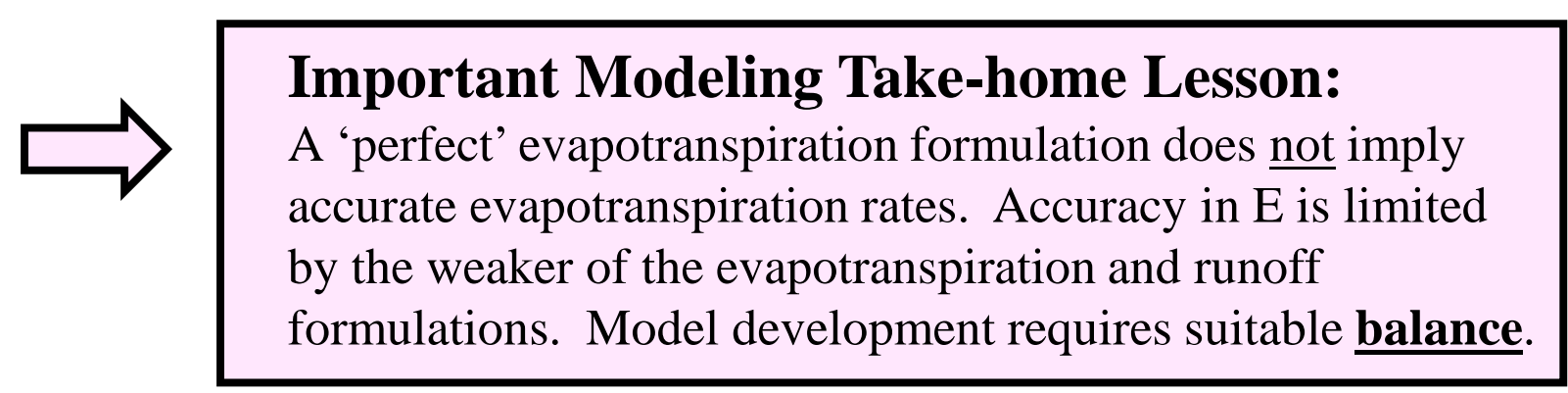


Also, soil moisture in a land surface model is a very model-dependent variable, more an 'index of wetness' than an actual physical quantity.

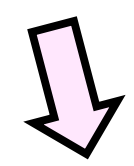

\section{Another Important Modeling} Take-home Lesson:

Taking soil moisture from one model (e.g., from a reanalysis) and using it in another can lead to serious problems. Scaling is essential.
Demonstration of problem: seasonal precipitation forecast skill

Using soil moisture ICs obtained from offline system $\mathrm{w} /$ same land surface model.
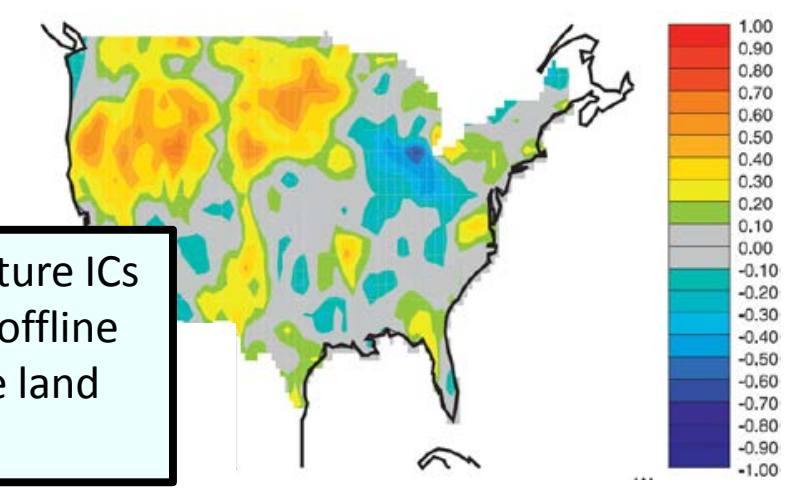

Using soil moisture ICs obtained from reanalysis that used different land surface model.

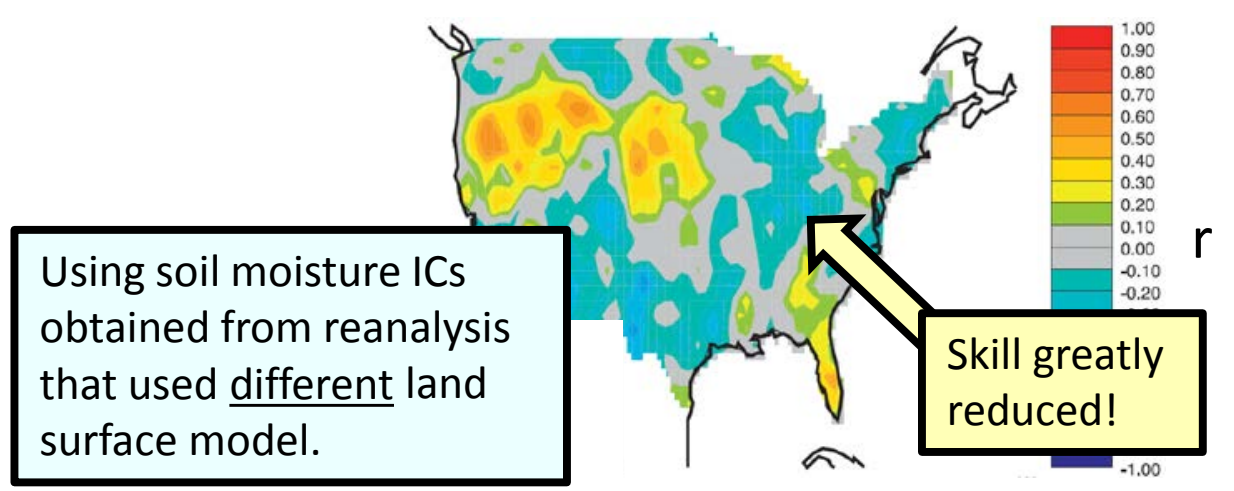




\section{A Few Summary Statements}

Variability in near-surface soil moisture can causally translate to variability in meteorological variables through the influence of soil moisture on the energy and water budgets at the land-atmosphere interface, particularly in transition zones.

This potential for feedback, combined with soil moisture's intrinsic memory, provides the basis for utilizing soil moisture information in monthly-to-seasonal forecasts.

The outlook for improved soil moisture estimation (e.g., for initializing forecasts) is optimistic given the advent of new satellite data, which can be assimilated into land surface models. Use of models, however, comes with important caveats:

- A model's overall performance is only as good as the weaker of its evapotranspiration and runoff formulations (not often appreciated!)

- Inserting soil moisture from one model (even from a trusted reanalysis) into another without performing climatology transformations can lead to significant problems (appreciated even less!) 